\title{
Aggression And The Telos Of Learning: A Psychoanalytic Study Of Significant Host-Foreign Language Acquisition
}

\author{
Fernanda Carrá-Salsberg, $\mathrm{PhD}^{1}$ \\ York University
}

\begin{abstract}
With a focus on descriptions provided in Richard Rodriguez' Hunger of Memory, Alice Pitt's "Language on Loan" and Alice Kaplan's French Lessons, this article analysis the psycho-emotional situation of significant language learning for both: child and adolescent monolingual migrants, and host-foreign language students studying abroad. It is an examination of the unconscious meaning behind linguistic relocations. This work pays close attention to the manner in which acquiring a new language unveils subjects' affect and history of learning. It looks into host-foreign language immersions and acquisition in relation to our human nature, universal needs and responses to host-foreign language immersions and learning. Drives and defenses behind young language migrants' embodiment of a new language are discussed through questions of desire, identifications and need for individuation. Central to this paper is also the exploration of how significant learning, as a cognitive-emotional experience, is tied to differing forms of aggression. This work asks: What can migrants' and foreign language students' desire to learn hostsecond languages tell us about their inner realities and about the meaning they knowingly and unknowingly attach to an acquired host-foreign language? How may host-foreign language acquisition aid in learners' psychic growth? To what extent does significant learning become a module in young subjects' process of self-reinvention? And finally, and at the heart of this article, how is significant language acquisition tied to crises, identifications and matricide?
\end{abstract}

\section{Introduction}

A topic debated during my doctoral defense touched upon the differences ostensibly marked between young migrants' and foreign students' host language acquisition. I remember how the phenomenological similarities between these learners were questioned and differences were brought to the fore. I suggested that the social and circumstantial realities that infringe upon both kinds of students create the ethos of their host/foreign language acquisition. I noted that such realities impact language learners' attitudes towards, and perceptions within, the target language. Founded on my own history, I described the manner in which young first generation migrants often feel a marked sense of doom by their exilic position. How becoming permanently uprooted from their known past and presumed future affects their needed sense of historical continuity. I proposed that for many underage migrants, following the initial excitement of being in a new land,

${ }^{1}$ Correspondence concerning this article should be addressed to Dr. Fernanda Carrá-Salsberg, Department of Languages, Literatures and Linguistics, York University, Toronto/Canada. E-mail: fcarra@yorku.ca 
their -possible- enthusiasm becomes tainted by the realization of their condition: for having been forced to leave the comfort of their native home, language, culture, and understood sense of self to become immersed within the terrain of the foreign other.

I contrasted my past perceptions as both, a child and later, an adolescent migrant with conversations I often have with my enthusiastic second language students. I highlighted their excitement when they approach me for letters of reference in support of their applications to study a foreign language abroad. I mentioned that unlike young migrants, exchange students have a pronounced sense of choice. For these undergraduate language learners, the prospect of living in a foreign land and culture is embraced as a temporary, welcomed and highly enriching experience. I compared my university students' attitudes with those of child and adolescent migrants and explained that for underage emigrants, migrating is barely perceived as a source of excitement. Their relocation is rarely interpreted as a privilege, even if in actuality it may be one. Instead, for those unwilling to migrate, their move is often felt as a long-term injustice, as a source of inner pain and inconsolable tears.

My memories of inner and social chaos were compared with my students' usual elation. I remembered how at the age of eight and later, as a seventeen year-old, I experienced no pleasure in unwillingly becoming a displaced child and later, an angry adolescent. There was no joy in leaving the comfort of family and friends to become a linguistic minority and therefore an outsider. The discussion brought me back to my times as a new migrant, when I felt embarrassed for being forced to speak without being understood. I was taken back to memories of feeling humbled for experiencing a need to belong while being repeatedly let down by my perceptual misfit. I recalled my attempts to interact with people my age while becoming marked by the absence of shared cultural histories, and of commonly understood signs, rules, words and sounds.

Months following my oral defense, on the night before my students' Spanish exam, I found myself struggling to write a cohesive opening for this article on host-foreign language learning and on its epistemological connection to crisis. Having no genuine notion of the paths through which my words would venture, I once again began to consider the circumstantial differences and similarities between the two types of language learners. I sat at my kitchen table feeling exhausted by the sight of language memoirs that stood before me. Even though they were migrant-narratives that depicted writers' memories of living between homes and languages, they were accounts that fell short of offering the taste of foreign language learning that Alice Kaplan's (1993) non-migrant, foreign language memoir evokes.

The thought of having to work with literature that only partially narrated the social and inner struggles of significant language acquisition ${ }^{2}$ drained me, so my tired thoughts took

\footnotetext{
${ }^{2}$ In this paper 'significant language acquisition' refers to the socio-cognitive, affective and transformational nature of learning a host language through immersion. Second language learning, on the other hand, makes reference to foreign language acquisition that is limited to language classrooms. Examples of significant language learners are migrants and foreign language students studying a foreign language within the compounds of its socio-cultural and linguistic reality. Specific to this paper, 'second language learners' refers to students who study a target language for a few hours a week, while living within linguistic and socio-cultural realities that differ from those of the symbolic code studied
} 
flight...I thought of my students' anxieties within and outside of our second language classroom, in connection to their commonly voiced desire to live within the compounds of a foreign/host language and culture. I felt a renewed sense of bewilderment by the antithesis of their in-class struggles and their hopes and daring considerations to study abroad. I then took a last look at my almost illegible notes and felt overtaken by a fleeting thought, which made me scribble:

For non-migrant, foreign language students, their choice to temporarily move away from their homes may create a space for them to escape from their realities, to hide and even reframe their identities under a more acceptable...perhaps even idealized light...

On the following morning, after coming home from giving my students their -much dreaded- exam, I noticed that without intending, my penciled words entered the realm of an initially unperceived problematic. The sentence bent on the uneven margin of my draft spelled a disjunction of meanings, one that pointed to the words 'choice' and 'necessity to escape'. The disjointedness of my words, which during the late hours of the night eluded me, led me to reconsider the concepts of 'need' and 'aggression' in relation to foreign students' efforts to embody a new language. Such insight created a space for me to reassess what may lie beneath the dynamics that give life to individuals' desire to become language migrants, to live in internal exile, and to reinvent themselves between languages. It allowed me question what may lie beneath their willingness to become estranged subjects within their own reality-driven narratives.

This accident of thought allowed me consider the relevance of not limiting my study to host-foreign language acquisitions that exclude the experiences described by foreign students learning a host language abroad. This slip of pen led to the examination of the nature of linguistic transformations undergone by both, migrant and non-migrant hostforeign language learners. Hence, while not disregarding the manner in which young migrants' internal and external exilic condition adds to the perceptual precariousness of their emotional lives, this paper pays close attention to the subjective meaning behind all linguistic relocations.

In this article I begin by setting a theoretical ground of the affective qualities of significant host-foreign language learning. While analysing the autobiographic narratives written by Richard Rodriguez, Alice Pitt and Alice Kaplan, I examine the psycho-social situation of linguistic immersions and host-foreign language acquisition. Such socioaffective moves are studied in relation to our human nature and "universal need for identifications, love, sense of belonging and temporal continuity" (Akhtar 2012). ${ }^{3}$ I consider how host-foreign language immersions and host-foreign language acquisition lead to the interruption of such needs, rendering subjects' sense of inner chaos. I also conceptualize the crisis that stems from significant language learning and ask how the eventual synthesis of this socio-cognitive and emotional experience relates to our nature and development within and outside of language.

This work is a look into pedagogic and psychoanalytic theories of learning and trauma. I examine how host-foreign language acquisition compares to other forms of significant

in foreign/second language classrooms.

${ }^{3}$ Expressed by the psychoanalyst Salman Akhtar in a 2012 conference held in Toronto, where he discussed migration, dislocation and trauma.

Language and Psychoanalysis, 2015, 4 (2), 34-49

http://dx.doi.org/10.7565/landp.2014.008 
learning, and ask: What can young migrants' and foreign language students' desire to learn host-foreign languages tell us about their inner realities and about the meaning they knowingly and unknowingly attach to an acquired host-foreign language? How may hostforeign language acquisition aid in the natural and significant process of learners' personal growth? To what extent does significant learning become a module or constituent in young subjects' process of self-reinvention? And finally, and at the heart of my study, how is significant language acquisition tied to matricide, crisis and aggression?

\section{Methodology}

This article links psychoanalytic and pedagogic theories of learning with interpretations of auto-biographic narratives of language acquisition. It focuses on the nature, constructions and meanings of adults looking back at their lived and imagined occurrences as child and adolescent language learners. My work is centred in the emotional and developmental meaning of significant language acquisition. It is a focus on subject reality and thus on the manner in which past experiences are perceived and therefore interpreted by writers. ${ }^{4}$

This paper studies the way in which autobiographic writings offer a view into writers' personal conceptions, perceptions, reflections, ideologies and understandings of hostforeign language immersions. I examine how lived and imagined incidents of language learning directly and indirectly unveil subjects' conscious and unconscious experiences. I consider the manner in which writers' retrospective and reconstructed occurrences offer an entrance to their private worlds, into constructions that are inaccessible with traditional forms of data collection (Pavlenko, 2007, pp. 164-165). The events described in Hunger of Memory, Language on Loan and French Lessons are not studied as facts, but as "system of meanings and interpretation" (p.168). These autobiographic narratives are analysed for the symbolic significance in their exposure to truths that are linked to the developmental telos of significant learning within language(s).

\section{A Psychoanalytic and Pedagogic Understanding of Significant Learning and its Relation to Host-Foreign Language Acquisition} In "Pedagogy and Clinical Knowledge", Britzman and Pitt present the manner in which the act of learning, as a cognitive phenomenon, taps into the learner's history of affect. They discuss individuals' response to new material and explain how foreign information, or data that does not fit within the learner's schemata, is felt as "a force that is not secured by meaning or understanding" (p. 369). They argue that the experience challenges learners' false sense of security and of mastery. The new data becomes involved within a dynamic that disables the subject's ability to make relations and therefore think (p. 366). Since the new information creates a "rupture of cognitive frames" (Felman, 1991, p. 56), the subject is left feeling anxious, helpless and, as a result, in a state of crisis.

\footnotetext{
${ }^{4}$ As explained by Pavlenko (2007) literary analysis draws from three interconnected types of information: subject reality, life reality and text reality. Subject reality is a look into how things or events were experienced by the narrator; life reality is a study of how things are and were, at the factors that influenced and still influence writers' ideologies and perceptions of events; and text reality is an examination of how occurrences are narrated by writers (p. 165).
}

Language and Psychoanalysis, 2015, 4 (2), 34-49

http://dx.doi.org/10.7565/landp.2014.008 
Britzman and Pitt suggest that the interruption caused by the act of learning, by the break between the old and the new, between what is part of a continuous frame of experience and that which disrupts, uproot individuals' known and unknown histories (pp. 371-372). This phenomenon, continue Britzman and Pitt, brings to light subjects' memories and phantasies of learning and not learning, as well as their repression(s) and resistance(s) to learn. Equally important, awakening individuals' history of object relations causes the inevitable rise of transference (pp. 368-369), as a force that, regardless of its connection with subjects' forgotten past, is felt as one that belongs to the present (Freud, 1935, p. 395; Klein, 1975, p. 48). Britzman and Pitt claim that once the tension that emerges from the subject's inner and outer realities becomes confronted through a negotiation between the ego and its environment, symbolization occurs and learners' experience is brought into relief through significance (pp. 369-370).

Conceptualizing the shock and sense of crisis that emerge through foreign linguistic immersions makes it commonsensical to link Britzman's and Pitt's descriptions of significant learning with host-foreign language acquisition. Learning and internalizing a language becomes more than a socio-cognitive experience. Yet the commonality of such intricate occurrence explains why the attention given to the affective side of second language learning is not, in its strict sense, a contemporary concern. Erwin Stengel (1939) has also suggested that within foreign linguistic immersions, language acquisition becomes an "anachronic" act that uproots the subject's past. In other words, the immersion into a foreign tongue places the subject back into a primary situation of language, taking the learner back to a forgotten history that preceded the use and/or proficiency of her first language. For this British psychiatrist and former migrant, when subjects are forced to communicate within a poorly known language, they re-live and therefore unknowingly respond to their infantile, repressed histories (p. 476).

Beyond theory, examples of the emotionality of host-foreign language acquisition are found in both, Pitt's Language on Loan and Kaplan's French Lessons. Beginning with Pitt (2013, p.40), when referring to her own experience as a foreign language student, she suggests:

... our history of having to learn intrudes. It reminds us of our helplessness and dependency, our fight with authority, as necessary as it may be, and our guilt at having abandoned our earliest loves -our parents and even our omnipotent child selves who could, if only in fantasy, make reality bend to our wishes and believe that infinity is ours to find in the starry night.

Likewise, when Kaplan (1993, p.128) shares her experiences as a foreign language student and a postsecondary foreign language educator, she calls the language classroom:

...the rawest pedagogy I have ever been in. A place where content means almost nothing and power, desire, provocation almost everything...Language learning can show up 
people's craziness in dramatic ways...famous stories about language learning...[are

about] battles of the will with fierce parental overtones.

Pitt and Kaplan speak to the internal and external dynamics that are at play within the context of in-class language learning. Their assertions give rise to a conflict that, according to Jen Gilbert, "is necessary for intellectual development" (p. 6). Equally important, their testimonies move our theory beyond the hierarchic dynamics that are indeed present within second language classrooms and within all interactions between individuals of differing linguistic proficiencies. Their words also speak of an added crisis that relates to the individual's sudden change in identity. Their recollections move my discussion beyond language socialization theory and the problem of becoming a linguistic minority: highlighting the trauma that stems from having to perform one's own ignorance by having to speak a poorly-known language.

\section{Significant Learning, Matricide and the Re-creation of the Self in Richard Rodriguez' Hunger of Memory}

In Reading Histories: Curriculum Theory, Psychoanalysis, and Generational Violence Jennifer Gilbert (2010) explains that reading entails innovation and transformation, murder and reparation. Through reflections drawn from a conference she attended on curriculum studies, as well as discussions on generational violence and on Arendt's concept of natality, Gilbert suggests that reading exposes a learner to ideas that allow her to "imagine worlds beyond the confines of the known" (p. 67). Her argument is also grounded in André Green's and Alice Pitt's psychoanalytic theories on reading and its stark relation to matricide. Beginning with Green, Gilbert quotes: "to read is to feed off the corpses of one's parents, whom one kills through reading, through the possession of knowledge" (cited in Gilbert, p. 67). Gilbert links Green's words with those of Pitt, who, in Mother Love's Education, explains that: "reading enacts unconscious phantasies of murder and reparation... an "act that is no less violently felt than if an actual murder has taken place" (cited in Gilbert, p. 67).

Following these quotes Gilbert proposes that a subject's encounter with knowledge changes the reader's sense of self and her relationship with her parents (p. 67). Gilbert describes that following the phantastical violence engendered through the acquisition of knowledge, what drives the child's desire to continue to read and thus introject "food for the mind" is the unconscious understanding that the mother survived her child's act of violence (pp. 67-68).

This psychoanalytic notion is difficult to ignore when studying child and adolescent second language acquisition. Consequently when revisiting Pitt's (2006) discussion in her article Mother Love's Education I understand that, as unimaginable as these words may seem for readers who are new to psychoanalytic thought, it is not difficult to link this phantasy to any significant learning that entails, by its very influence, a perceived transformation. Matricide becomes a part of every child's developmental need to transform by moving away from her earliest days and times of dependence from her first love object. As Pitt explains, in its psychoanalytic sense, this unconscious act gives way to the birth of a child's psychic reality, or a reality interconnected with aggression, symbolization, guilt and need for reparation (pp.87-88). Equally important, this creative 
replacement is needed for infants' development into speaking beings. Such developmental act is key to the child's loss of the unspoken self and transition into language; it is born through and within the child's membership to the wider community of competent speakers (pp. 88-90).

When looking closely into language-related narratives, the prevalence of this affective situation becomes evident. It is explicitly found, for example, with Richard Rodriguez (1983) in his memoir Hunger of Memory. In this well-known and highly controversial memoir, Rodriguez offers his reasons for opposing both, bilingual education and affirmative action programs in the United States. With a focus on his own education and his coming of age within the host, English language, this 1.5-generation MexicanAmerican migrant begins his narrative with descriptions of a happy, early childhood. In the initial sections of his text, Rodriguez reflects upon his childhood Spanish and his early interactions with his parents and siblings. Quoting from Rodriguez (1983, pp. 1415):

Español: my family's language. Español: the language that seemed to me a private language. My parents would say something to me [in Spanish] and I would feel embraced by the sound of their words. Those words said: I am speaking with ease in Spanish. I am addressing you in words I never use with los gringos. I recognize you as someone special, close, like no one out-side. You belong with us. In the family (Ricardo)... I lived in a world magically compounded with sounds...delighted by the sounds of Spanish at home.

Rodriguez describes the turn of events that took place upon entering the AmericanCatholic school system. While reminiscent of that moment in time, Rodriguez narrates about his in-class silence and about the struggles he experienced as a monolingual Spanish speaker. He exposes the events of his life that took place before his linguistic and academic difficulties were overcome through the exposure to English in both at school and eventually at home. ${ }^{5}$ One of the most prominent aspects of Rodriguez' narrative is not limited to the ease in which he acquired the host-English language. Instead, it relates to the excitement he eventually experienced through his exposure to English written texts, and to the manner in which the acquisition of knowledge -learned at school- resulted in guilt (pp. 28, 30) and in a silencing void between himself and his parents (pp. 24, 27).

In his memoir Rodriguez offers an incidental reverberation of Pitt's matricidal discussion. By introducing Richard Hoggard's description of a scholarly child, Rodriguez, who consistently refers to himself as a scholarly student, cites: "a scholarly boy...cannot forget that his academic success distances him from a life he loved, even from his own

${ }^{5}$ Rodriguez explains that following his teachers' suggestions, his parents began speaking English in their home with noticeable Spanish accents and "ungrammatical speech" (pp. 19-20, 25).

Language and Psychoanalysis, 2015, 4 (2), 34-49 
memory of himself..." (p. 51). Later in that same page Rodriguez adds: “...parents become the figures of lost authority....the scholarly boy cannot afford to admire his parents" (p. 51). Equally important, the isolating conflict and inner guilt endowed by Rodriguez' (1983, p.54) love for reading and for learning new concepts are highlighted when he writes:

I kept so much, so often, to myself. Sad. Enthusiastic. Troubled by the excitement of coming upon new ideas. Eager. Fascinated by the promising texture of a brand-new book. I hoarded the pleasures of learning. Alone for hours. Enthralled. Nervous. I rarely looked away from my books - or back on my memories...I slipped quietly out of the house. It mattered that education was changing me.

Rodriguez' school and library books not only opened doors to new knowledge: Texts exposed him to the acquisition and eventual internalization of the host English language. Reading and learning introduced him to an entirely new reality, to a wider community of speakers and, according to this writer, to a new and improved social status. For this 1.5generation Mexican-American migrant, learning English offered him a subjective change, one which translated into an eventual break from the discrimination and poverty suffered by his own Spanish-dominant parents (see pp. 51, $56 \& 58-59$ ).

Yet for Rodriguez, encountering a world of a new language and of ideas that resided outside of his home created a conflict born from destruction and creation, or, quoting from Rodriguez, "loss and gain" (p. 27). His highly politicised narrative offers, nevertheless, concreteness through a rationalized example of the possible dynamics that give way to reading and thus to the violence defined by matricide: by an act that becomes intertwined with individuals' conscious and unconscious desire to give up their earliest childhood condition by altering their inner and social selves through learning.

\section{Affective Aspects of Studying Abroad in Alice Pitt's Language on Loan}

Similar to Rodriguez' memoir, in Language on Loan, Pitt (2013) offers her own recollections of learning German as both, a second language student in Canada and later, a host-foreign language learner in Germany. In her paper Pitt interconnects descriptions provided in Alice Kaplan's (1993) French Lessons with her own experiences as a foreign language student. She shares her view on the epistemological and affective significance of a learned -and internalized- foreign language. Pitt proposes that becoming a speaking subject in another language exposes the learner to the interminable play between constraint and creativity. She explains that the transformative nature of this specific learning act produces thrills and anxieties, loss and renewal, mastery and forgiveness. Second language learning, recalls Pitt, become "experiences of transfigurations" (p. 37).

In her article Pitt taps into the emotional quality of foreign language acquisition, suggesting that acquiring another language provokes "passionate, eroticized experiences that... might be akin to falling for poetry or music or visual art" (p. 42). Pitt speaks of the 
antagonistic feelings she experienced through the acquisition, and/or reacquisition, of German. Such is read, for example, when Pitt recalls feeling "enveloped" and "romanced" by the sounds of German (p. 38), and later feeling frustrated as well as impatient through her struggles to keep up with the challenges of becoming proficient in a foreign symbolic code (pp. 39-40).

Most of us know that if one truly needs to learn another language, the process of its acquisition gives way to an encounter with fears as well as thrills and excitement. Based on my own remembered occurrences, the act of significant language learning can easily turn into an experience that, in my opinion, can be equated with that of an indisputable roller-coaster-ride of confounding emotions. Yet in Language on Loan Pitt offers more than my recent claim. Her descriptions give voice to the pedagogical and affectual space that genuinely precedes linguistic expression, one that is lived by learners who desire a language that is only beginning to be inhabited. Following the stage that Granger (2004) highlights and terms as that of "silence" in second language learning, Pitt describes entering the phase in which the new language is no longer a source of distress, when it is no longer persecutory, feared and/or rejected. Quoting from Pitt (2013, p. 37):

The idea that children growing up in Germany saw a plate where I saw an abyss woke me right up to the power of language to represent the world. It was not God that created the world; it was language, and I had just been let in on the mystery. In that instant, the problem of translation vanished, and my German lessons became experiences of transfiguration.

Here Pitt describes the period in which the foreign language becomes appreciated for its symbolic and epistemological nature: when acquiring a subsequent symbolic code begins to offer its newest learners a creative alternative to self-expression. When learners encounter the much-anticipated space in which they can feel almost re-born through the world offered by the new language.

\section{The idealization of host-foreign language learning in Alice Kaplan's French Lessons: A Module for Adolescents' Self- invention, Symbolization and Individuation}

In French Lessons Alice Kaplan testifies to her memories of language learning and thus of the life-changing experiences within and outside of French, Kaplan's acquired second language. In this memoir she offers phenomenological descriptions of her experiences abroad as a foreign language learner. She shares her personal reasons for hiding behind an adopted language: her necessity to escape from the emptiness caused by her father's sudden passing and from the anxieties that resulted from the incompatibility she experienced with her sick and lonely mother. Readers may also note that her choice to acquire and internalize the French language was not only fuelled by her loss and sensed crisis, but also by her adolescent need to idealize that which lied outside of her Englishspeaking world. Becoming immersed within the compounds of the French language, not only allowed her to move away from a confining reality she openly rejected, it also fed 
her desire to rebel and to become renewed through a genuine process of selftransformation.

Descriptions provided in Kaplan's self-narrative complement those of Winnicott (2005), who explains that the basis of all learning, as well as eating, is emptiness (cited in Britzman \& Pitt, 2004, p. 365). For Kaplan, French became the language that allowed her to fill her inner void. As with Pitt (2014), Kaplan's acquisition of French became a source of nourishment, one that almost replaced her need to eat. As presented by Pitt (2013, p. 42) in Language on Loan: "She [Kaplan] more or less stopped eating, and she chased the language her fellow students spoke, but mostly she chased French".

For Kaplan, French was the language to cover pain, one that enabled her attempt to start over. Such attempt, however, was later affected by the guilt of her matricidal act, and her unconscious need to work through such developmental conflict. As seen in Rodriguez' memoir, Kaplan's text offers readers a glimpse of the way in which internalizing a new symbolic code draws the learner to a perceptually acceptable, new and often idealized reality. Specifically, in French Lessons Kaplan (1993, pp. 40-41) depicts the projection of an idealized transformation is conceivable under Leaving, for example, when she recalls meeting with Ted and feeling excited by the romanticised prospect of studying in Switzerland and incidentally, by becoming transformed by her welcomed adventure: "I loved imagining coming home, suave and seductive, before I even left...on the other side of the world...I would be a new person. I wouldn't recognize Ted anymore. I wouldn't even understand his [English] language".

One important aspect worth highlighting is Kaplan's imagined assumption of a sudden and complete linguistic shift. Another pertinent detail relates to the location in which she chose to bare farewell to her friend Ted and presumably to her monolingual, teenage life in Minnesota. Not only does her last reunion take place in a cemetery, but when she and Ted look for a particular place to kiss, they chose to lie beside and eventually over the corpse of a young woman who shared Kaplan's first name. In the final section of Leaving Kaplan (1993, p. 41) writes:

The marble on Alice Bergstrand's grave was refreshing. Ted's kisses came faster. I got dizzy from the cold of the marble, the warmth from Ted's mouth; I felt myself cutting, cutting through time and place, slipping through a trap door into another world... With my hands on the marble, I propped myself over him. His eyes were closed...I looked around me... I could see the lake with a few sailboats on it, across Lake Calhoun Boulevard. It wasn’t my home anymore. It was a landscape.

For Kaplan, moving abroad signified an internal relocation of homes, a way out of her present life and a way into a highly romanticized reality. When preparing to leave, Minnesota becomes "a landscape". It reflects a part of her rejected present and remembered past. The realization and idealization of a language's transformative nature, 
of its ability to temporally pull her away from her understood past, turned her French lessons into an exhilarating experience (Kaplan, 1993, pp. 55-56).

This writer's acquired French became her transitional language. French developed into the symbolic code that invoked her sense of inner growth: one that spelled while enabling the underlying intent of matricide. Such unconscious act moves the subject away from the old self and the oppressive love that signifies his or her first object and times of dependency. Such inner growth allows for the individual to find symbolization through the development of a new form of expression, of novel meanings, unfamiliar relations and, equally important, the transformational sense of becoming a new persona.

\section{Desire and the bidirectional aggression in significant host-foreign language learning: What does it mean to identify with the aggressor?}

Relevant to my discussion of language learning is the dynamics of a complex, multidirectional intersection of aggression and desire. By looking closely into the act of host-foreign language acquisition, we can derive the presence of a well-defined violence that points to our nature and, borrowing from Freud, to our civilized discontents. ${ }^{6}$ Within the process of language acquisition, aside from the aggression exercised towards one's mother and oneself, there is a violent force that is projected from the outside towards the learner. This is seen in Kaplan's narrative, specifically when she claims that: "It is violent being thrown into a new language and in having to make your way. Violent and vulnerable: in a new language, you are unbuttoned, opened up" (p. 139). This acknowledgement is also discussed by Pitt, who, in "Language on Loan" makes reference to the conflict and helplessness inflicted upon the learner when becoming submerged into the world of foreign language learning. Such helplessness and conflict, moreover, is perceived when subjects are immersed into a reality that, according to Pitt, uproots while exposing the "vulnerability of our human nature" (p. 6). Here we note how Kaplan's and Pitt's words address the aggression suffered by those who become immersed within the borders of a foreign language. It is a violence that, in agreement with Deborah Britzman and Alice Pitt, is constitutive of all significant learning.

Yet it seems incomplete to discuss the aggression that exists within the dynamics of hostforeign language learning without reconsidering the authority that emanates from a host language, and the threat perceived by learners through their social and inner "struggles to keep up" (Pitt, 2013, p. 39). In relation to this phenomenon, Britzman (2006) argues that when confronted with the vulnerability and helplessness inflicted by an object's authority, subjects, in their attempt to turn passivity into activity and free themselves from the oppressing aggressor, commit the libidinal act of introjecting all or parts of the object with the motive of destruction and defeat (pp. 45, 49-51). By applying this defense the subject becomes active and no longer feels like a victim; She breaks free from oppression and echoes the aggressor in her desire to dominate.

${ }^{6}$ In Civilization and Its Discontents Sigmund Freud while defining people as split subjects, describes subjects' universal needs and outlines the known and unknown aggression that is innate to each and every one of us. Freud argues that such an aggression often becomes sublimated through art, and/or controlled by religion and by society's codes of civilized, social conduct. Society's imposition and governance over our natural inclination or nature, suggests Freud, is at the root of our human discontents (pp. 103104). 
Within the terrain of foreign language immersions one can assume that linguistic minorities unknowingly turn passivity into activity. They commit the libidinal act of introjecting or absorbing all or parts of the foreign language and culture. Such unconscious act is seen with Rodriguez (1983, p. 52) when he describes his interactions with his primary-school teachers while considering his identification with authority:

I began by imitating their accents, using their diction, trusting their very direction.

The very first facts they dispensed, I grasped with awe. Any book they told me to read, I read -then awaited for them to tell me which books I enjoyed...it was the nun's [teacher's] encouragement that mattered most to me

Rodriguez' (1983, p. 58) memory of his own identification with his teachers becomes further evoked in that same section when he mentions:

When I was in high school, I admitted to my mother that I planned to become a teacher someday. That seemed to please her. But I never tried to explain that it wasn't the occupation of teaching I yearned for as much as it was something more elusive: I wanted to be like my teachers, to possess their knowledge, to assume their authority, their confidence, even to assume a teacher's persona.

For this writer, the embodiment of the host language was achieved through his identification with teachers who symbolized, while highlighting, the host linguistic and social authority. It is significant to also add that the undercurrent that feeds a subject's desire to master a new language is also unquestionable in Kaplan's memoir. Such is read, for example, when Kaplan (1983, pp. 93-94) describes her ranting interpretation of André's rational for leaving her and worse yet for replacing her apparent love with that of Maïté's:

It's because my French isn't good enough" and "It's because she is French." When he told me I couldn't understand his language, André had picked the accusation I was most vulnerable to. Afterwards I thought, "I'll show him. I know all there is to know about his language. I'll know his language better than he does, someday.”....I wanted to breathe in French with André, I wanted to sweat French sweat. It was the rhythm 
and pulse of his French that I wanted, the body of it, and he refused me, he told me I

could never get that. I had to get it another way.

It is almost inconceivable for me to read these narratives without connecting them to my past and present experiences within languages. This focus makes me reconsider my own conscious and unconscious motives to learn, relearn and obsess with the language that as a child I felt as other. I assume it should be no surprise that as an undergraduate student I decided to drop psychology as a declared major to pursue the study of the Spanish language. Furthermore, as a young adult, I became obsessed with its sounds, rules and linguistic irregularities. Not only did I feel the pressing need to master the Spanish language, in time I switched my role within the foreign-language classroom: from student to instructor.

My academic choice allowed me to re-discover the Spanish language, to understand its grammar, its irregularities and thus to make it perceptually mine. Even though English is the language I currently live and breathe, Spanish turned into the language I truly know, the one held within my childhood tears and dreams, the one that reflects the otherness that will always exist within the inner compounds of my known and unknown self.

\section{Conclusion}

Language is not a machine you can break and fix with the right technique, it is a function of the whole person, an expression of culture, desire, need. Inside our language is our history personal and political (Kaplan,1993, p. 98).

As expressed by Kaplan, a lived language is a representation of the self, of the speaker's desires, wishes and histories. Through language subjects are able to transform themselves, understand and represent their lived and imagined worlds. An internalized language is also a vehicle through which individuals learn about their social and inner realities, about the essence that resides within the self and the otherness that gives away subjects' known and unknown histories. In this article I studied the socio-emotive and cognitive similarities of migrants' and non-migrants' host/foreign language acquisition. Similar to Pitt, Rodriguez and Kaplan, I chose to work within an area that speaks to my experiences and life within competing languages. I assume that the engagement with topics that are perceived as irreducibly ours often grants us with the drive to stay afloat within the difficulties perceived through our encounter with difficult knowledge. Yet the problem we could stumble upon when addressing circumstances linked to our own known and seemingly forgotten histories relates to the exposed and sometimes hidden affect that is at play with our qualitative interpretations.

It is not ground breaking to claim that when we are emotionally involved with a topic, we may unknowingly become influenced by a perspective that, instead of sweeping across the broadness of an entire picture, becomes partial in its one-sided view and understanding of events. A year following my defense I can now say that in spite of my experiences as a young migrant, a postsecondary second language educator and a translingual subject, my initial argument was lacking in discursive neutrality. When discussing the phenomenology of foreign language learning, the thick, red line I traced dichotomizing the types of socio-linguistic and cognitive experiences -that of migrant 
and non-migrant language learners- obstructed my view. It blinded me of the universality of our common desire to belong and, at times, of our need to hide or run-away from experiences and situations that may make us feel confused, unsatisfied and possibly, incomplete.

My preliminary view of the young, exiled migrant made me take sides. My own recollections did not allow me to conceptualize the affective experiences encountered by those who, regardless of perceived choice, also enter the world of foreign languages and desire: the affective world of idealizations, of linguistic dislocations, challenged identities and intersemiotic translations. ${ }^{7}$ I am not denying how young migrants' precarious, imposed position taints their initial attitude towards their new situation and language. I am also not ignoring how the hostile perception of their newfound experience increases their sensed crisis. Yet considering Akhtar's (2012) words and thus understanding our universal need for love, safety, identifications, sense of belonging and continuity, we cannot refute that even among those who opt to study abroad, becoming immersed within the borders of the foreign becomes an experience that threatens their universal needs: their feeling of belonging, of emotional safety, their unconscious relation with their first loves and sense of socio-linguistic continuity.

With the narratives studied we know that Rodriguez' memoir served a political purpose of opposing both, bilingual education and affirmative action programs in the United States. Through his autobiography this writer justifies the rejection of his heritage language, explaining that learning English as a child aided in his education and career advancement. In his opinion his success was unrelated to his positioning as a MexicanAmerican migrant. Instead it was linked to the internalization of the dominant language and the eventual rejection of his mother tongue. Pitt's and Kaplan's narratives, on the other hand, testify to the emotionality of adolescent host-foreign language learning. Similar to Rodriguez, these writers and former foreign language students highlight the transformative nature of their host-foreign linguistic acquisition and foreign language use. Yet in spite of the different circumstances that inspired Rodriguez, Pitt and Kaplan to learn, internalize and claim host-foreign languages as their own, and regardless of the reasoning(s) behind their decision to share the construction of their past and present memories, studying their descriptions led to a psychoanalytic interpretation of the experiential commonalities in migrants' and foreign students' language learning experiences. Their accounts created a space for the analysis of the vicissitudes of significant language learning and its relation to crisis, trauma, creativity and aggression.

Whether host-language learners are involuntary migrants or voluntary language students acquiring a host language abroad, with foreign-linguistic immersions aggression is

${ }^{7}$ Intralingual translations are defined as translations between signs of the same language. From a post-structural perspective we understand that language and culture are not fixed or stable entities, thus one creates signification [with a Bakhtinian orientation: one creates one's own accent] from through plural, fluid, non-unitary categories that build upon the phenomenological production of diverging and often conflicting signs. Intersemiotic translations speak to this fluidity. Its focus is not limited to the one language. Instead, it looks into the meaning-makings that are communicatively produced and understood through the interaction and 'passage' between linguistic and non-linguistic signs, between language and cultures that, from a subjective perspective, are in contact with one another (Karpinski, 2012, pp. 3-6).

Language and Psychoanalysis, 2015, 4 (2), 34-49

http://dx.doi.org/10.7565/landp.2014.008 
eminent through the loss and replacement of a language that is representative of their first loves. Aggression also emanates from the precariousness of individuals' vulnerability as learners, and from the uprooted fears and anxieties that become juxtaposed with their need for independence. For migrant and non-migrant host language students, significant language acquisition surpasses the act of encoding a new set of symbols and grammatical rules. It is also more than an introjection of new beliefs and ways of life. Significant language learning involves crisis, destruction, creativity and innovation. This act forms part of a telos or purpose that enables subjects to willingly and unwillingly, consciously and unconsciously, distance themselves from their old selves and earliest loves. The aggression experienced through significant language acquisition enters the arena of the many matricidal acts that are driven by individuals' universal nature, by their innate need and desire to grow and develop through the process of destruction, reconstruction and eventual transformation.

\section{Biographical Note}

Fernanda Carra-Salsberg has been a postsecondary foreign language educator for the past fifteen years. Born in Buenos Aires, Argentina, her interest in language, culture, migration and identity formations stems from her repeated migrations as a child and an adolescent, and from experiences as a language pedagogue. She has taught English as a Second language and Spanish. Carra-Salsberg is currently teaching elementary and intermediate Spanish Grammar and Spanish for Native Speakers at York University, Ontario, Canada.

Carra-Salsberg has obtained a Bachelor of Arts Degree with Honours in Spanish Language, Literature and Linguistics at York University, a Bachelor of Education Degree in Second Language Acquisition and History at the University of Toronto's Ontario Institute for Studies in Education, a Master's in Arts Degree in Spanish Language and Literature at the University of Toronto. She has also completed a Doctor of Philosophy Degree in Language Acquisition, Language Philosophy and Psychoanalysis at the Faculty of Education, York University. 


\section{References}

Akhtar, S. (2012). Strange lands: Location and dislocation: The immigrant experience. Presented at the $18^{\text {th }}$ Annual Day in Applied Psychoanalysis, Toronto, Ontario, September.

Akhtar, S. (1995). A third individuation: Immigration, identity, and the psychoanalytic process. Journal of American Psychoanalytic Association, 43, 1051-1084.

Britzman, D. (2006). A note on "identification with the aggressor. In Novel Education: Psychoanalytic Studies of Learning and Not Learningpp. 41-60). New York, NY: Peter Lang.

Britzman, D. \& Pitt, A. (2004). Pedagogy and clinical knowledge: Some psychoanalytic observations on losing and refinding significance. JAC Online 24 353-374.

Retrieved from http://www.jaconlinejournal.com/archives/vol24.2.html

Felman, S. (1991). Education and crisis, or the vicissitudes of teaching. In S. Felman \& D. Laub (Eds.). Testimony: Crisis of witnessing in literature, psychoanalysis and history (pp. 1-56). New York, NY: Routledge.

Freud, S. (2002). Civilization and its discontents. New York, NY: Penguin. (Original work published 1930).

Freud, S. (1975). A general introduction to psychoanalysis. New York: Liveright Publishing. (Original work published 1935).

Gilbert, J. (2010). Reading histories: Curriculum theory, psychoanalysis, and generational violence. In E. Malewski (Ed.). Curriculum studies handbook: The next moment (pp. 63-72). New York, NY: Routledge.

Granger, C. (2004). Silence in second language learning: A psychoanalytic reading. London, UK: Cromwell Press.

Green, A. (2004). Experience in thinking, André Green at the Squiggle Foundation. Buffalo, NY: Multilingual Matters.

Kaplan, A. (1993). French lessons: A memoir. Chicago, IL: University of Chicago Press.

Karpinski, E. (2012). Borrowed tongues: Life writing, migration and translation. Waterloo, ON: Wilfred Laurier University Press.

Klein, M. (1975). Envy and Gratitude and Other Works 1946-1963. New York, NY: Free Press.

Pitt, A. (2006). Mothers love's education. In G. Boldt \& P. Salvio (Eds.), Love's return: Psychoanalytic essays on childhood, teaching and learning (pp. 87-106). New York, NY: Routledge.

Pitt, A. (2013). Language on loan: Mediations on the emotional world of language learning and teaching. In J. J. Plews, \& B. Schmench (Eds.), Traditions and transitions: Curricula for German (pp. 37-48). Waterloo, ON: Laurier Press.

Rodriguez, R. (1983). Hunger of memory: The education of Richard Rodriguez. New York, NY: Bantam Books.

Stengel, E. (1939). On learning a new language. International Journal of Psychoanalysis, 20, 471-479. 